\title{
The role of time perspective in coping behavior
}

\author{
Alla K. Bolotova, Milana R. Hachaturova \\ National Research University Higher School of Economics, Moscow
}

\begin{abstract}
This article describes research on the role of time perspective in a person's choice of coping strategies in interpersonal conflicts. The interrelationship between different types of coping strategies (cognitive, emotional, and behavioral) and the orientation of time perspective are considered. P. G. Zimbardo's technique, which defines the orientation of time perspective, and E. Heim's technique, which is directed at exploring coping strategies, are used in our research. The sample consisted of 295 participants: 156 women and 139 men, with an average age of 32 years. The research shows that a future orientation is directly connected with the choice of cognitive and behavioral coping strategies in interpersonal conflicts, while an orientation to the negative past results in emotional coping strategies. A person's orientation to the fatalistic present engenders retreat and avoidance of conflict resolution, which are nonadaptive behavioral strategies that include few coping techniques.
\end{abstract}

Keywords: time, time perspective, coping strategies, interpersonal conflict

An extremely important component of a person's mental health and psychological well-being is the ability to independently define the purposes of one's life, and also to have available in one's image of the world an extended and substantial time perspective, oriented to the future. Time is one of the important but extremely little used resources of a person's mental organization and self-realization in society. As a consequence, in intricate social conflicts or difficult life situations, the loss of time perspective means the loss of one's life purposes, and is one of the symptoms of an approaching life crisis. In human formation and development, time determinants become an integral element of personality structure, consciousness, and the "developing-person" criterion (Zinchenko \& Morgunov, 1994). Therefore, a person's time perspective can be considered as an indication of an ability to handle difficult situations and to choose strategies for coping with them. As Zinchenko and Morgunov (1994) note, people can develop their personalities only when they are time-conscious: when they master time and create their own time.

Another Russian psychologist, L. S. Vygotsky, points out that "human formation into an individual and personality assumes a specific combination or time coincidence of internal development processes with external conditions, which is typical for each age-stage of ontogenesis" (1982, p. 108). Hence, the formation of 
time perspective becomes a means of self-control, and of developing coping strategies in difficult situations. Today, studying the development of time perspectives, not only in the context of personality formation but also in the context of the development of coping strategies in conflict situations, has become a matter of primary importance. The theoretical-methodological basis of research in Russian psychology is presented by Vygotsky in his cultural-historical approach to understanding a person and her/his formation. The implementation of this approach has found its continuation and further development in the works of such prominent psychologists as L. I. Bozhovich, A. N. Leontiev, A. V. Zaporozhets, and D. B. Elconin, and also in the works of S. L. Rubinshtein and K. A. Abulhanova-Slavskaya on the problems connected with the course of life and personal time, and also on the concept of personality chronotope highlighted by A. A. Uhtomsky, M. M. Bakhtin, and V. P. Zinchenko.

\section{Time perspective}

In Russia, psychological problems related to a person's time perspective have been discussed by K. A. Abulhanova-Slavskaya, T. N. Berezina, A. K. Bolotova, E. I. Golovaha, A. K. Kronik, I. S. Kon, N. N. Tolstyh, E. N. Osin, A. Sircova, and others.

With regard to the experience of time, Rubinshtein (1977) has put forward the idea of a person's course of life, a subjective picture of his/her life. Rubinshtein stresses the necessity of taking into account a person's ability to change his or her life. Another of Rubinshtein's concepts covers the subject of life and the principle of personality analysis through life activity.

In foreign psychology the notion of time perspective has been introduced by Kurt Levin (2001), who views it as a person's vision of his or her future and past in the present. In addition, the cognitive choice and emotional experiences connected with past or future events can have an impact on the person's activity here and now, and can motivate future actions. B. V. Zeigarnik, Levin's pupil and a well-known Russian psychologist, believes that past experience, being an essential characteristic of a person's dynamics, can play an important role in determining life perspectives, setting time milestones, and reaching objectives. Zeigarnik points out that the ability to give a more or less objective assessment of a situation from the point view of its present and future development, and to find a way to set feasible goals, is a necessary and important condition for the formation of human personality (Zeigarnik, 1971).

In his works, Frank (1939) defined the concept of time perspective as the influence of past experience and future plans on the process of decision-making and behavioral patterns in the present. In 1985 Joseph Nutten, in accordance with Levin's idea of the fullness of life space in time, put forward a thesis that the concept of time perspective appears under the influence of a person's cognitive evaluation of his/ her needs and intentions. Having agreed with Levin on the question of the impact of past and future experiences on behavior in the present, Nutten (2004) emphasized the specific influence of the future. He stressed that the formation of time perspective is determined not merely by a person's past experience, but also by cognitive analysis of his/her plans for life, and thus the formation of time perspective provides a basis for individual motivation. 
The latest works in the area of time-perspective research have been presented by Brissette, Scheier, and Carver (2002), D’Alessio, Guarino, Pascalis, and Zimbardo (2003), and Zimbardo and Boniwell (2004).

Time perspective is one of the overall characteristics of a personality. It plays an important role in life processes and events, affects many spheres of human activity, and is connected with different personality features. The importance of studying time perspective is explained, above all, by the influence that the person's thoughts on his/her past and present may have on the efficiency of his/her activity in the present.

Time perspective as an integral construct is connected with many personal features; it is capable of influencing different aspects of a person's behavior, including behavior in difficult situations, which are more widespread nowadays due to the instability and unpredictability of the social situation and the growth of social-psychological intensity. A belief in the occurrence of only negative events in the near future is often observed in conflict situations. It can be considered one of the factors in stress. The expectation of an unpleasant event is generally harder to endure than the event itself (Bolotova, 2007, 2012).

\section{Coping behavior}

A person's coping behavior plays an important role in resolving difficult conflict situations that may arise in various spheres of life. In Heim's (1988) opinion, coping behavior shows itself in the cognitive and emotional actions that a person takes to overcome difficult situations and to adapt to existing circumstances.

This concept was first used by L. Merfi in 1962 to research behavioral patterns that children employed to cope with problems in personality formation and developmental crises (Karvasarskii, 2000). The coping problem was thoroughly studied in the context of psychological stress by Lazarus (1993), who regarded coping as the behavioral and cognitive efforts undertaken by a person to decrease the influence of stressful circumstances. Now, the idea of coping is used in studies of behavior in every difficult life situation.

There are various classifications of coping strategies in psychological research. For example, Heim (1988) has suggested considering emotional, cognitive, and behavioral strategies. These three types of coping behavior vary in accordance with degree of adaptiveness: adaptive, relatively adaptive, and nonadaptive.

The problem of coping with difficult conflict situations is now treated by many Russian and foreign psychologists through the "resource approach." This theory assumes that there are certain specific personality features that help to overcome difficulties (Bodrov, 2006; Folkman \& Lazarus, 1998; Hobfoll \& Lerman, 1988; Holahan \& Moos, 1987; Taylor, 1995; Vodopianova, 2009; and others). Time perspective in this context is one of these significant features.

As Zimbardo and Boyd (1999) claimed, time perspective can be regarded as a person's constant feature. However, time perspective has its own situational characteristics due to being affected by the person's cultural, social, and age characteristics, economic and marital status, educational background, or religious beliefs. 
Thus, it would appear that during a person's life, time perspective can vary under the influence of his/her career achievements; significant events; changes in economic, social, and political environment; and successes and failures (Sircova \& Mitina, 2008).

\section{Connections between time perspective and coping behavior}

In foreign psychology a number of researchers have studied the connection between choice of coping strategies and personality characteristics - in particular, time perspective. Among them are Epel, Bandura, and Zimbardo (1999), Folkman and Lazarus (1998), Wills, Sandy, and Yaeger (2001), Worrell and Mello, (2007).

In Boniwell and Zimbardo's research (2004), time perspective was used as a predictor of various actions taken by a person. Respondents in these experiments were put in conditions similar to a "prisoner's dilemma." The researchers discovered that in such situations, future-oriented and past-oriented people were more inclined than present-oriented people to cooperate, as they realized that cooperation could lead them to the desirable goal more quickly than other strategies. Present-oriented people behaved in an irrational way; they worked at random, without any planned tactics, and they seldom used cooperation. Thus, Boniwell and Zimbardo stress the importance of time perspective in the choice of coping strategies in difficult and conflict situations. A balanced time perspective can help a person to cope with difficulties and complicated situations because of its influence on coping behavior.

Brissette and colleagues (2002) found that a person oriented to the future is inclined to think about and control all aspects of a difficult situation. At the same time, he/she is optimistic and believes that self-efficacy will help resolve the conflict.

In Russian psychology, the problems connected with the interrelationship between time perspective and the choice of coping strategies in difficult situations in general, and in conflict situations in particular, have been examined in the works of Abulhanova-Slavskaya (1991), Alekseeva (2002), Arestova (2000), Ryabinkina (2007), Sircova (2008), Sircova and Mitina (2008), Tolstyh (2010), and others.

Research conducted by Alekseeva (2002) shows that the degree of personal involvement in the process of coping with difficult life situations increases with age. It is expressed, first of all, in one's taking responsibility for existing conflicts, and this in itself has a great impact on the choice of specific coping behavior.

Sircova and Mitina (2008) have proven the existence of a correlation between a balanced time perspective and such indicators as intelligence, endurance, satisfaction, and adaptive coping strategies.

The results obtained by Ryabinkina (2007), Belinskaya (2009), along with other researchers, show that in a conflict situation, future-oriented people choose such coping strategies as self-control, searching for ways to solve the problem, and distancing. This behavior can be characterized as being based in a desire to dismiss the problem for a certain period of time in order to consider ways of solving it rationally. A person with a time perspective focused on the past can positively reevaluate the situation and accept responsibility for an existing conflict. At the same time, the person can try to find positive aspects in the conflict that will enable him/ her to avoid similar errors in the future. The research shows that coping strategies 
connected with the search for social support can be chosen by both past-oriented people and those focused on the future. This finding proves the universality of this strategy because communication with significant people can be regarded both as a resource from past experience, on which the person falls back during difficult times, and as part of the future.

Working on the construct of time perspective, Boniwell and Zimbardo (2004) described a "balanced time orientation," which combines five factors: when high points prevail in the person's positive past and future orientations, when middle points are at the scale of the hedonistic present, and at the same time, when low points are at the scale of the negative past and fatalistic present. A well-balanced time perspective provides flexibility, which allows a person to shift among the events of the past, present, and future in response to life circumstances and situations. The behavior of a person whose construct shows high indicators is determined by a balance between the influence of past experience, the purposes of the present, and appropriate thoughts about the future. According to Sircova and Mitina (2008), this combination of time orientations is optimal for the psychological and physical health of a person, and also for his/her adaptation to and effectiveness in society.

Despite the importance that time perspective can have in choosing coping strategies in conflict situations, the topic has not been thoroughly researched in modern Russian psychology.

\section{Research project}

\section{Methodology}

Modern research on time perspective basically uses the methodology of the Zimbardo Time Perspective Inventory (ZTPI) (Zimbardo \& Boyd, 1999), which was developed by P. Zimbardo in cooperation with A. Gonzalez and allows simultaneous work with all three aspects of time - the past, the present, and the future. The ZTPI method consists of five factors, or scales: the negative past, the hedonistic present, the positive past, the fatalistic present, and the future. In our work we have researched the connection between time perspective and choice of behavioral coping strategies in an interpersonal conflict by applying Zimbardo's technique (in Sircova's (2008) adaptation) and also Heim's inventory (1988), which explores various types of behavioral coping strategies.

\section{Participants}

The sample included 295 participants; 139 of them were male, and 156 were female. The average age was 32 years.

\section{Results and discussion}

The Statistical Package for the Social Sciences (SPSS) 14.0 was used for statistical data processing (descriptive statistical data, differential criteria, correlation analysis). The data was verified against the normality of distribution by applying Kolmogorov-Smirnov's test, asymmetry, and excess indicators. The obtained distribution of the variables relevant to personality characteristics investigated in the 
research did not differ from the normal distribution. This result allowed us to use the parametrical technique.

Table 1 describes the time-perspective orientation of the sample as a whole.

Table 1. Description of Time Perspective for the Entire Sample

\begin{tabular}{lcccc}
\hline \multicolumn{1}{c}{ Scale } & Mean & Standard deviation & Asymmetry & Excess \\
\hline Negative Past & 2.47 & 0.74 & 0.35 & -0.73 \\
Hedonistic Present & 3.42 & 0.54 & -0.25 & -0.24 \\
Future & 3.71 & 0.55 & -0.35 & 0.01 \\
Positive Past & 3.74 & 0.59 & -0.35 & 0.74 \\
Fatalistic Present & 2.51 & 0.65 & 0.32 & -0.24 \\
\hline
\end{tabular}

Table 2. Spearmen Correlations Between Time Perspective and Choice of Coping Strategies

\begin{tabular}{|c|c|c|c|c|c|}
\hline Coping strategies & $\begin{array}{l}\text { Negative } \\
\text { past }\end{array}$ & $\begin{array}{c}\text { Hedonistic } \\
\text { present }\end{array}$ & Future & $\begin{array}{c}\text { Positive } \\
\text { past }\end{array}$ & $\begin{array}{c}\text { Fatalistic } \\
\text { present }\end{array}$ \\
\hline Analysis of problem & 0.011 & 0.026 & $0.172^{\star}$ & -0.029 & 0.127 \\
\hline Self-possession & $-0.232^{*}$ & $-0.126^{*}$ & $0.356^{* *}$ & -0.086 & -0.043 \\
\hline Awareness of own importance & -0.117 & $-0.277^{* *}$ & $0.318^{* *}$ & $-0.134^{*}$ & -0.099 \\
\hline Relativity & 0.038 & 0.059 & 0.057 & 0.039 & 0.052 \\
\hline Religiousness & -0.062 & -0.044 & $0.189^{* *}$ & -0.098 & -0.051 \\
\hline Searching for sense & 0.089 & 0.021 & 0.029 & 0.015 & 0.099 \\
\hline Ignoring the problem & 0.034 & 0.034 & $-0.309^{* *}$ & -0.045 & 0.093 \\
\hline Humility & 0.152 & 0.089 & $-0.312^{* *}$ & -0.072 & 0.099 \\
\hline Dissimulation & $0.317^{*}$ & 0.044 & $-0.226^{*}$ & -0.017 & -0.026 \\
\hline Confusion & $0.255^{\star *}$ & -0.017 & -0.053 & -0.059 & 0.017 \\
\hline Protest & -0.075 & 0.046 & $0.273^{\star *}$ & 0.126 & $-0.334^{* *}$ \\
\hline Optimism & -0.043 & $0.214^{*}$ & $0.282^{* *}$ & $0.321^{\star}$ & -0.069 \\
\hline Emotional relief & 0.079 & 0.042 & 0.021 & $0.266^{\star *}$ & 0.045 \\
\hline Passive cooperation & $0.117^{\star}$ & $0.114^{*}$ & -0.062 & 0.085 & 0.078 \\
\hline Suppression of emotions & $0.424^{\star *}$ & -0.022 & -0.057 & -0.044 & $0.313^{\star *}$ \\
\hline Obedience & $0.351^{\star *}$ & 0.056 & $-0.258^{\star}$ & 0.061 & $0.418^{\star \star}$ \\
\hline Self-accusation & 0.093 & 0.039 & -0.019 & -0.059 & $0.274^{\star \star}$ \\
\hline Aggression & 0.092 & $0.268^{\star \star}$ & $-0.265^{\star *}$ & -0.021 & $0.173^{\star *}$ \\
\hline Cooperation & $-0.313^{* *}$ & 0.043 & $0.127^{\star}$ & $0.268^{\star *}$ & -0.076 \\
\hline Altruism & $-0.292^{\star *}$ & -0.065 & 0.026 & $0.326^{*}$ & -0.093 \\
\hline Communication & $-0.465^{\star *}$ & -0.081 & $0.275^{\star \star}$ & $0.225^{\star}$ & $-0.191^{\star *}$ \\
\hline Distraction & 0.058 & 0.052 & -0.017 & $-0.141^{\star}$ & 0.069 \\
\hline Indemnity & 0.041 & $0.321^{*}$ & 0.059 & 0.032 & 0.026 \\
\hline Constructive activity & -0.037 & $-0.199^{*}$ & $0.134^{*}$ & -0.031 & -0.043 \\
\hline Active avoidance & 0.051 & $0.232^{*}$ & $-0.355^{\star *}$ & 0.019 & $0.361^{* *}$ \\
\hline Retreat & $0.388^{\star *}$ & $0.271^{\star}$ & -0.091 & 0.042 & $0.225^{\star *}$ \\
\hline
\end{tabular}

Note. ${ }^{*} p \leq 0.05{ }^{* *} p \leq 0.01$ 
High indicators on the scales of the future and the positive past, a moderate value on the hedonistic present scale, and low points on the factors of the negative past and fatalistic present, show that a person possesses a balanced time perspective. Of the respondents taking part in the research, $41 \%$ possessed such a perspective.

As an outcome of the research, we found a correlation between the choice of coping strategies and a person's time perspective. Table 2 shows statistically significant correlations. As the correlation coefficient does not allow us to determine the direction of the connection, it is necessary also to consider Figures 1 and 2, which present the percentage parity of the choice of types and variants of coping strategies against the orientation of time perspective.

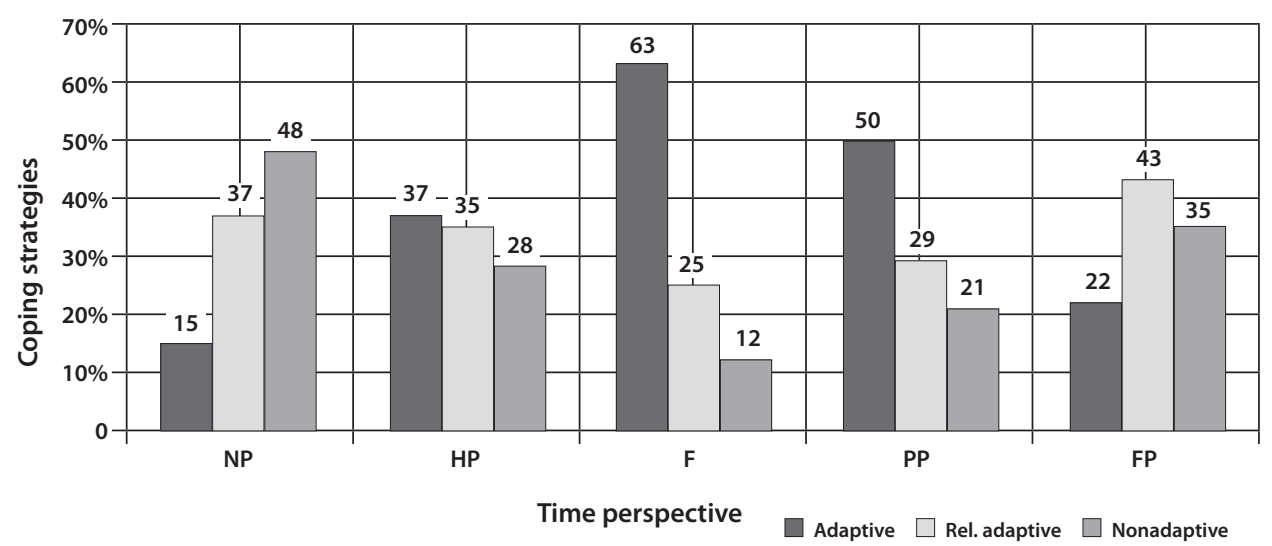

Figure 1. The choice of types of coping strategies depending on orientation of time perspective.

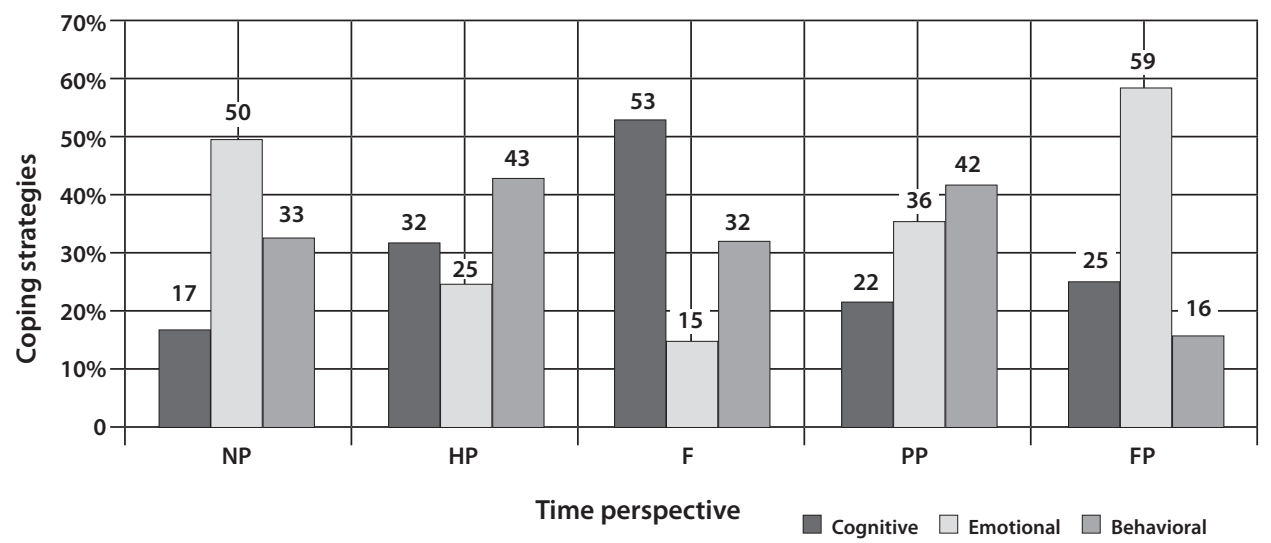

Figure 2. The choice of variants of coping strategies depending on orientation of time perspective.

Statistical analysis proves that the future-oriented person is inclined to choose adaptive cognitive strategies in a conflict situation. Such people are selfcontrolled, and try to analyze the existing conflict and find possible ways to resolve it. Also, time-perspective orientation to the future significantly correlates 
with the choice of cognitive adaptive strategies. In conflicts, such people often turn to others, cooperate with them, and make a joint effort to overcome the difficult situation. The future-oriented person understands that in some cases, in order to save the relationship with his opponent or to avoid future negative consequences, it is better to use a cooperation strategy than confrontation and animosity. At the same time such people try to be optimistic and believe in their own ability to cope with the conflict. The aspiration to set goals and efforts made to achieve them, along with active participation in the events of their own lives, allow them to turn to strategies that avoid conflicts and help them to retreat from the existing difficulties.

The research suggests that a person's time orientation to the fatalistic present notably correlates with the choice of relatively adaptive and nonadaptive emotional strategies in conflicts: suppression of feelings, self-blame, obedience, and aggressiveness. It is also connected with the choice of nonadaptive behavioral strategies of active retreat and avoidance. At the same time, this time perspective negatively correlates with the choice of adaptive emotional and behavioral strategies of protest and cooperation. In a conflict situation such people try to suppress their emotions, considering themselves to have been offenders, or on the contrary they can become aggressive and release their emotions onto others.

In this way such people try to avoid the problems emerging in a conflict situation. Fatalistic-oriented people regard their future to be predetermined and simply accept life as it is, without seeing the necessity of taking action in order to affect the situation. For them it is simpler to avoid the conflict and to concentrate on the emotional side of the problem.

Orientation to the fatalistic present is not notably connected with any one of the cognitive strategies. People who do not trust their self-efficacy in coping with a conflict situation and who believe that the future has already been predetermined are not inclined to analyze the problem, think of ways of solving it, and make their own decision; instead they rely either on other people or on the circumstances.

The negative past is the only time orientation that reveals a substantial connection with the choice of all types of nonadaptive coping strategies. It notably correlates with the strategies of dissimulation, confusion, suppression of emotions, obedience, and retreat. It has a negative correlation with the choice of adaptive types of cognitive and behavioral strategies, such as self-possession, altruism, and cooperation.

The prevalence of this time orientation can be explained by the fact that a person's past contains injurious and unpleasant experiences that have had an impact on his/her personality formation. Therefore, when the person faces a conflict, a new unpleasant situation, he or she tries to avoid the problem, retreat, and suppress negative emotions. Cognitive analysis of the reasons that may have led to the conflict, and a search for ways out of it, are not the main strategies for such a person. The combination of nonadaptive emotional and behavioral coping strategies proves to be unproductive; such strategies cannot teach the person to cope with difficulties effectively.

The orientation to the positive past has a negative correlation with the choice of cognitive strategies and, at the same time, positively correlates with the choice of 
adaptive emotional and behavioral strategies such as optimism, cooperation, altruism, and communication. As we have already pointed out, a person thinking about the past has many nostalgic moments and strong positive emotional experiences. Therefore, when such a person faces a conflict situation, he/she tries to remain optimistic and believes that his/her self-efficacy will help to handle the conflict. Such people try to acquire useful experience from conflict situations. Besides, they often consider cooperation and communication with other people to be an important resource when coping with difficulties.

It would appear that coping strategies connected with the search for social support can be chosen by both people oriented to the positive past, and those focused on the future. As we have already mentioned, this feature proves the universality of this strategy, because communication with significant people can be regarded both as a resource from past experience which the person uses at difficult moments, and as part of personal future plans. We can find evidence of the universality of this concept in other research (Belinskaya, 2009).

A person's orientation to the hedonistic present is connected with the choice of optimism as an emotional strategy, and also with nonadaptive emotional and behavioral strategies such as aggression, retreat, and active avoidance. However, this time orientation has a negative correlation with the choice of adaptive cognitive strategies of self-possession and awareness of one's own importance. A person oriented to the hedonistic present has a desire to live a full life and enjoy it here and now, instead of thinking about the future. Consequently, in a conflict situation such people try to be optimistic and to retain confidence in a positive outcome despite temporary difficulties. They retreat and try to avoid the arising problem because it may interfere with the usual comforts of their lives. But in case of failure, they can resort to the strategy of emotional outbreak and aggressive behavior.

In addition, in the orientation of time perspective among the respondents of our research, some significant differences were found with regard to the degree of variability of coping behavior. We understand variability of coping behavior as the respondents' choice of seven or more coping strategies in a conflict situation. Statistically significant differences were noticed in the orientation of time perspective to the fatalistic present and to the future (Mann-Whitney $\mathrm{U}$-criterion $p=0.04$ and $p=0.03$, respectively).

The majority of future-focused respondents (56\%) demonstrated variability of coping behavior. They realized that strategies leading to success in different situations of interpersonal interactions vary. At the same time, as has already been mentioned, people focused on the fatalistic present do not see any benefit in their actions, and therefore their coping behavior in conflict situations is rigid. Thus, $61 \%$ of these respondents chose only two or three strategies in conflict situations. Therefore, a time-perspective orientation to the negative past assumes the choice of the least adaptive coping strategies, and orientation to the fatalistic present leads to the choice of rigid strategies and to the relative absence of behavioral variants in conflict situations. 


\section{The research allows us to draw the following conclusions:}

1. Time perspective is a person's view of the future or the past in the present. The events of the future or past develop in reality, and influence the activity of the person here and now. It is important to see these events as they interact and to assess their influence on the events in the present.

2. Time perspective can influence different aspects of a person's behavior, including behavior in conflict situations.

3. In a conflict situation, a time perspective oriented to the future leads to the choice of cognitive and behavioral coping strategies, while orientation to the negative past is connected with the choice of emotional coping strategies.

4. The orientation of time perspective to the fatalistic present predicts the choice of nonadaptive behavioral strategies such as retreat and avoidance to resolve a conflict. Time perspective focused on the positive past is connected with the choice of adaptive behavioral and emotional coping strategies.

5. Time perspective focused on the hedonistic present is connected with emotional coping behavior in conflicts, and both adaptive and nonadaptive coping strategies.

6. The orientation of time perspective to the negative past leads to the choice of the least adaptive coping strategies, and orientation to the fatalistic present results in the relative absence of different coping strategies.

\section{Conclusion}

The findings of our research can be put to use in social-psychological training in developing time representations, and they can also be used in the process of psychological counseling on resolving conflicts in interpersonal relationships.

\section{References}

Abulhanova-Slavskaya, K. A. (1991). Strategii zhizni [Strategies of life]. Moscow: Thought.

Alekseeva, E. V. (2002). Proyavlenie otvetstvennosti podrostkov $v$ sovladanii s zhiznennymi problemami [The display of adolescents' responsibility in coping with life problems] (Unpublished doctoral dissertation). St. Petersburg: Herzen State Pedagogical University of Russia.

Arestova, O. N. (2000). Operacional'nye aspekty vremennoi perspektivy lichnosti [Operational aspects of a person's time perspective]. Voprosy psichologii [Issues of psychology], 4, 61-68.

Belinskaya, E. P. (2009). Koping kak socialno-psichologicheskaya problema [Coping as a social-psychological problem]. Psikhologicheskie issledovaniya, 1(3). Retrieved from http:// psystudy.ru

Bodrov, V. A. (2006). Psikhologicheskii stress: Razvitie i koping [Psychological stress: Development and coping]. Moscow: PER SE.

Bolotova, A. K. (2007). Chelovek i vremya v poznanii, deyatel'nosti, obshenii [Man and time in cognition, activity, and communication]. Moscow: HSE.

Bolotova, A. K (2012). Time parameters of nonverbal communication and personal communicative competence. Psychology in Russia: State of the Art, 5, 289-300. doi: 10.11621/ pir.2012.0017 
Boniwell, I., \& Zimbardo, P. G. (2004). Balancing one's time perspective in pursuit of optimal functioning. In P. A. Linley \& S. Joseph (Eds.), Positive psychology in practice (pp. 165-178). Hoboken, NJ: Wiley.

Brissette, I., Scheier, M. F., \& Carver, C. S. (2002). The role of optimism and social network development, coping and psychological adjustment during a life transition. Journal of Personality and Social Psychology, 82, 102-111. doi: 10.1037/0022-3514.82.1.102

D’Alessio, M., Guarino, A., Pascalis, V., \& Zimbardo, P. G. (2003). Testing Zimbardo’s Stanford Time Perspective Inventory-Short Form: An Italian study. Time and Society, 12, 333-347. doi: 10.1177/0961463X030122010

Epel, E. S., Bandura, A., \& Zimbardo, P. G. (1999). Escaping homelessness: The influences of self-efficacy and time perspective on coping with homelessness. Journal of Applied Social Psychology, 29, 575-596. doi: 10.1111/j.1559-1816.1999.tb01402.x

Folkman, S., \& Lazarus, R. S. (1998). Coping as a mediator of emotion. Journal of Personal and Social Psychology, 54, 466-475. doi: 10.1037/0022-3514.54.3.466

Frank, L. (1939). Time Perspectives. Journal of Social Philosophy and Jurisprudence, 4, 292-312.

Heim, E. (1988). Coping and psychosocial adaptation. Journal of Mental Health Counseling, 10, $136-144$.

Hobfoll, S. E., \& Lerman, M. (1988). Personal relationships, personal attitudes, and stress resistance: Mothers' reactions to their child's illness. American Journal of Community Psychology, 16(4), 565-589. doi: 10.1007/BF00922772

Holahan, C. J., \& Moos, R. H. (1987). Personal and contextual determinants of coping strategies. Journal of Personality and Social Psychology, 52(5), 946-955. doi: 10.1037/0022-3514.52.5.946

Karvasarskii, B. D. (2000). Psikhoterapevticheskaya enciklopediya [Encyclopedia of psychotherapy]. St. Petersburg: Piter.

Lazarus, R. S. (1993). Coping theory and research: Past, present and future. Psychosomatic Medicine, 55, 237-247.

Levin, K. (2001). Dinamicheskaya psihologiya: izbrannye trudy [Dynamic psychology: Selected works]. Moscow: Sense.

Nutten, J. R. (2004). Motivaciya, deistvie i perspectiva bydyschego [Motivation, action and future perspective]. Moscow: Smysl.

Rubinshtein, S. L. (1997). Chelovek i mir [Man and world]. Moscow: Science.

Ryabinkina, I. V. (2007). Structurnaya organizatiya vremennoi perspectivy starshykh ychenikovs raznym yrovnem ychebnoi yspeshnosti [The structural organization of the time perspective of senior pupils with different levels of educational success] (Unpublished doctoral dissertation). Saint Petersburg State University, St. Petersburg.

Sircova, A. (2008). Vozrastnaya dinamika vremennoi perspectivy lichnosty [Age dynamic of a person's time perspective] (Unpublished doctoral dissertation). Moscow City PsychologicalPedagogical University, Moscow.

Sircova, A., \& Mitina, O. V. (2008). Vozrastnaya dinamika vremennyh orientacii lichnosti [Age dynamic of a person's time orientations]. Voprosy psichologii [Issues of psychology], 2, $41-54$

Taylor, S. (1995). Stimulus estimation and the overprediction of fear: A comment on two studies. Behaviour Research and Therapy, 33(6), 699-700. doi: 10.1016/0005-7967(95)00001-E

Tolstyh, N. N. (2010). Hronotop: Kul'tura i ontogenez [Chronotope: Culture and ontogenesis]. Smolensk and Moscow: Universym.

Vodopianova, N. E. (2009). Psikhodiagnostika stressa [Psychodiagnostics of stress]. St. Petersburg: Piter.

Vygotsky, L. S. (1982). Voprosy teorii i istorii psichologii [Problems of psychological theory and history] In Sobranie sochineni [Collected works] (Vol. 1, p. 108). Moscow: Pedagogics. 
Wills, T. A., Sandy, J. M., \& Yaeger, A. M. (2001). Time perspective and early-onset substance use: A model based on stress-coping theory. Psychology of Addictive Behaviors, 15(2), 118125. doi: 10.1037/0893-164X.15.2.118

Worrell, F. C., \& Mello, Z. R. (2007). Scores of academically talented adolescents: The reliability and validity of the Zimbardo Time Perspective Inventory. Educational and Psychological Measurement, 67(3), 487-504. doi: 10.1177/0013164406296985

Zeigarnik, B. V. (1971). Lichnost' i patologia deyatel'nosti [Personality and the pathology of activity]. Moscow: Moscow State University.

Zimbardo, P. G., \& Boyd, J. N. (1999). Putting time in perspective: A valid, reliable individual-differences metric. Journal of Personality and Social Psychology, 77(6), 1271-1288. doi: 10.1037/0022-3514.77.6.1271

Zinchenko, V. P., \& Morgunov, E. B. (1994). Chelovek razvivayushiisya [Developing man]. Moscow: Trivola.

Received: 22 December 2012

Accepted: 18 February 2013

Available Online: 27 November 2013 